\title{
First report of Penicillium purpurogenum causing collar and root rot infection in Aloe vera
}

\author{
Avasthi $\mathbf{S}^{1}$, Gautam $\mathrm{AK}^{2}$ and Bhadauria $\mathbf{R}^{1}$ \\ ${ }^{1}$ Mycology and Plant Pathology laboratory, School of Studies in Botany, Jiwaji University, Gwalior (MP) - 474011, \\ India \\ ${ }^{2}$ Faculty of Agriculture, Abhilashi University, Mandi (HP) - 175045, India,
}

Avasthi S, Gautam AK and Bhadauria R 2015 - First report of Penicillium purpurogenum causing collar and root rot infection in Aloe vera. Plant Pathology \& Quarantine5 (1), 20-24, Doi $10.5943 / \mathrm{ppq} / 5 / 1 / 4$

\begin{abstract}
Typical symptoms of infection were observed on collar and roots of Aloe vera plants in various nurseries and botanical gardens of Gwalior, Madhya Pradesh, India, mainly during rainy and winter seasons of 2010 and 2011. Infected collar showed dark maroon-brown spots of variable size, while root rot infection appeared in the form of browning and decaying of root tips followed by rotting of total root system. Penicillium purpurogenum was isolated from infected collar and root parts and Koch's postulates were confirmed. This is the first report of P. purpurogenum causing collar and root rot of Aloe vera in the world.
\end{abstract}

Key words - Aloe vera, collar rot, Penicillium purpurogenum, root rot.

\section{Introduction}

Aloe vera (L.) Burm. f. is an indigenous medicinal plant, having a long and illustrious history in Biblical and ancient Egyptians times. In India A. vera is popularly known as Ghikawar, Gwarpatha and Ghritakumari. It is a small, stem-less or very short stemmed, herbaceous, xerophytic plant. It has a shallow and spreading root system, and can grow up to $80-100 \mathrm{~cm}$ tall. Leaves are long, thick, fleshy, fibrous and lanceolate, with spiny margins, and are arranged in a rosette or alternate pattern. It is mainly cultivated in Alwar (Rajasthan), Satanapalli (Andhra Pradesh), Rajpipla (Gujarat) and some parts of Tamil Nadu, Madhya Pradesh and Maharashtra (Maiti \& Chandra 2002). A. vera contains 75 nutrients and 200 bioactive compounds including sugars, anthraquinones, saponins, vitamins, enzymes, minerals, salicylic acid and amino acids (Dureja et al. 2005, Boudreau \& Beland 2006). These bioactive compounds are used as astringent, haemostatic, anti-diabetic, antiulcer, anti-septic, anti-bacterial, anti-inflammatory, anti-oxidant and anti-cancer agents and are also effective in the treatment of stomach ailments, gastrointestinal problems, skin diseases, constipation, radiation injury, wound healing, burns, dysentery and diarrhoea (Yongchaiyudha et al. 1996, Bunyapraphatsara et al. 1996, Rabe \& Staden 1997, Gordon \& David 2001). 


\section{Materials \& Methods}

\section{Sample Collection and Isolation of Pathogen}

Samples of $A$. vera plants showing typical symptoms were collected randomly from the nurseries and botanical gardens, placed into labelled zip lock bags and brought to the laboratory for further analysis. Infected parts of $A$. vera i.e. collar and roots were washed thoroughly with running tap water to remove the adhering soil particles and then cut into small pieces. These pieces were surface sterilized with $2 \%$ sodium hypochlorite $(\mathrm{NaOCl})$ for 2 min and then washed three or four times in sterile distilled water. Under aseptic conditions surface sterilized pieces were placed on petri plates containing culture media. The media used were potato dextrose agar (PDA) and Czepak Dox agar (CZA). Plates were incubated at $25 \pm 2{ }^{\circ} \mathrm{C}$ for 5 to 6 days and the growth of fungus was recorded every day. The isolated fungus was identified on the basis of cultural and morphological characteristics as described by Gilman (2012).

\section{Pathogenicity Test}

The isolated fungus was evaluated for its pathogenicity against $A$. vera. Healthy 120 day-old plants were grown in $25 \mathrm{~cm}$ diameter plastic pots containing autoclaved sandy loam soil artificially infested with the test fungal isolate. Soil was infested by adding $200 \mathrm{ml}$ of hyphal or spore suspension $\left(4 \times 10^{7} \mathrm{ml}\right)$ of the fungal culture and then filled in plastic pots. A set of pots without fungal inoculum served as control. Soil was irrigated every 3-4 days to ensure equal distribution of fungal inoculum. The experiment was performed in triplicates and pathogenicity was evaluated at $25,35,45$ and 60 days after inoculation.

\section{Results}

\section{Natural Symptoms}

On naturally infected plants the collar rot occurred near ground level from where the leaves emerged. Initially infected plants showed spongy, scattered red spots on the collar region. These spots gradually enlarged and became dark maroon-brown in colour. When infected plants were pulled from the soil, stem mostly broke at the collar region. When roots were infected, the rot extended towards the collar region. Infected roots were dry, thin, curled, and brown to black in colour and there was a lack of new roots. In acute infection, rapid wilting and death of plants were observed. It was also noticed that when the infected plants died, a citron green fungus was visible on the roots and in soil around the roots (Fig. 1).

\section{Identification of Causal Pathogen}

Colonies on PDA were closely floccose, light greenish at first, then became yellowish green in colour and finally turned citron green with white margins. Reverse side showed orange to deep red pigmentation which is the main characteristic feature of the fungus. Conidiophores arise from aerial mycelium. Conidia were elliptical to sub-globose, 3.4-3.8 $\times 2-2.5 \mu \mathrm{m}$, smooth and pale green (Fig. 2). Based on morphological and cultural characteristics the fungus was identified as Penicillium purpurogenum Stoll. The identification was confirmed by the National Fungal Culture Collection of India (NFCCI), Agharkar Research Institute, and Pune, India, where the culture was deposited (\# NFCCI 2306).

\section{Pathogenicity Test}

Penicillium purpurogenum was pathogenic in glass house conditions and the symptoms of collar and root rot infection recorded during the pathogenicity test were similar to the natural symptoms. The rotting initially started at the root region and proceeded towards the collar. After 31 days red spots were observed on the collar of the plants. Gradually the spots enlarged, and became soft and dark maroon in color. Rotting appeared in the form of browning and decaying of root tips. 
Rooted roots were dry, thin and brown in colour. After 53 days symptoms spread towards the distil portion of roots, which resulted in total rotting of the root system.

\section{Discussion}

Penicillium purpurogenum is a known pathogen for several plant hosts. It has been reported as a fruit rot pathogen of strawberry (Gubler \& Converse 1994), Averrhoa bilimbi (Dahanayaka \& Wijesundera 1994) and Prunus armeniaca (Bhadwal \& Sharma 2011). P. purpurogenum has also been isolated from the rhizosphere of Aesculus indica (Sagar \& Kaur 2010) and as endophyte from Acorus calamus (Shukla \& Mishra 2012), Ziziphus sp. (El-Nagerabi et al. 2013). To the best of our knowledge, this is the first report of $P$. purpurogenum causing root and collar rot of $A$. vera in the world.
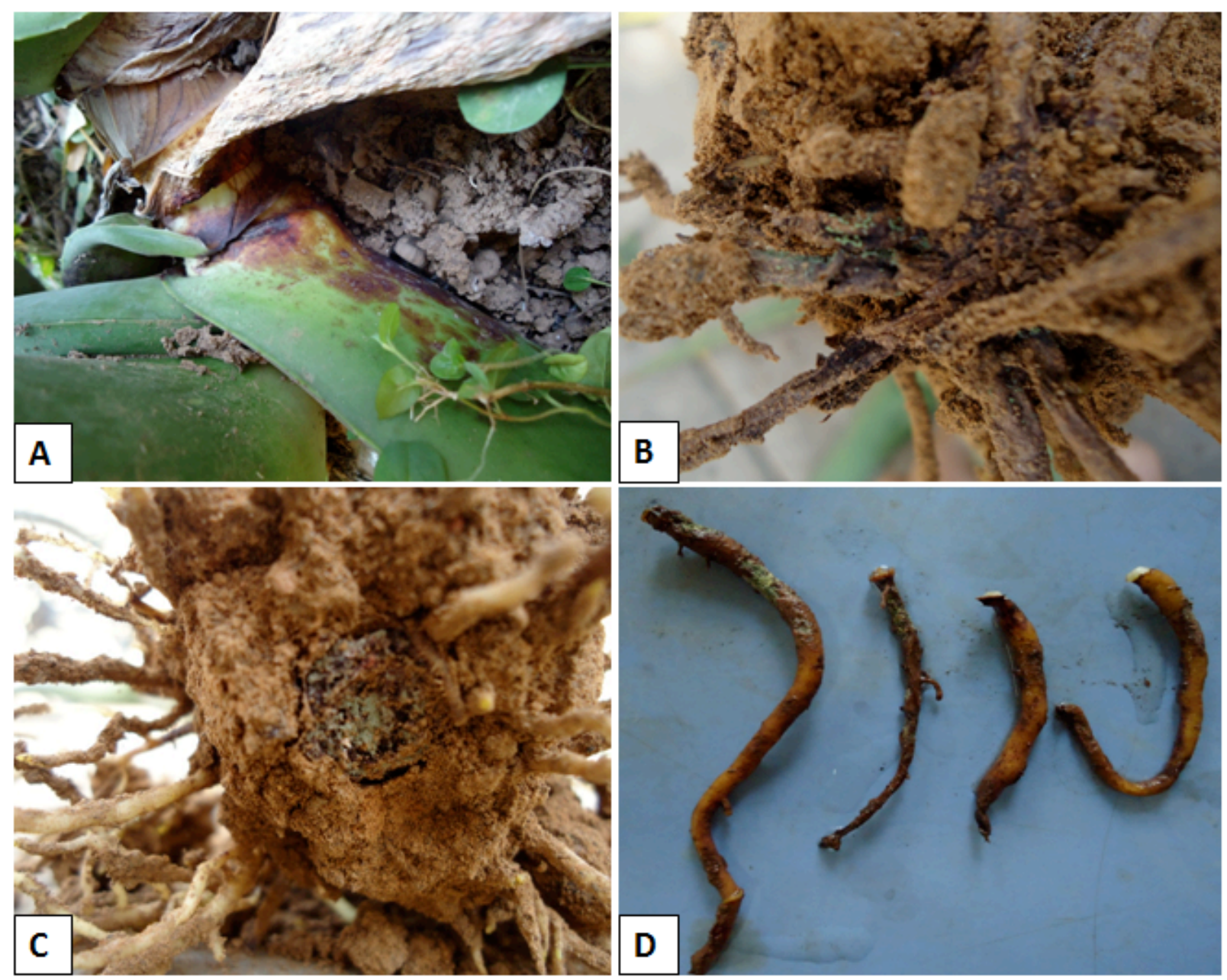

Fig. 1- Disease symptoms on Aloe vera. A, Infection on collar region. B-D, Infection on roots. 

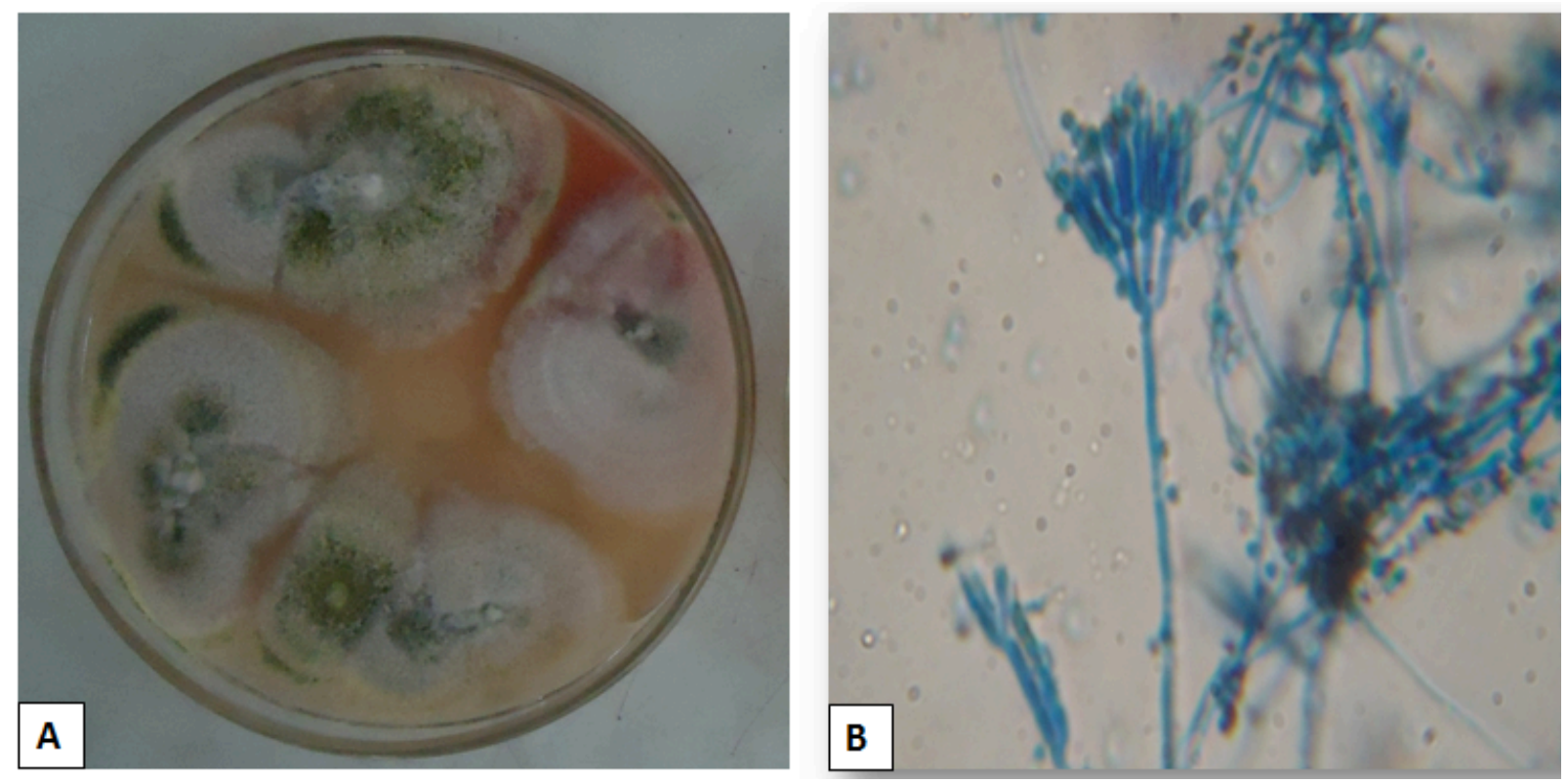

Fig. 2- A, Ten day old colonies of Penicillium purpurogenum on PDA. B, Microscopic view of Penicillium purpurogenum showing conidiophores, phalides and conidia.

\section{Acknowledgements}

The authors are grateful to Head, School of Studies in Botany, Jiwaji University Gwalior, Madhya Pradesh, India for providing laboratory facilities and support to conduct this research work.

\section{References}

Bhadwal J, Sharma YP. 2011 - Unrecorded post harvest fungal rots of fresh apricots from India. Proceedings of the National Academy of Sciences, India, Section B 88, 288-290.

Boudreau MD, Beland FA. 2006 - An evaluation of the biological and toxicological properties of Aloe barbadensis (Miller). Journal of Environmental Science and Health, Part C Environmental Carcinogenesis and Ecotoxicology Reviews 24, 103-154.

Bunyapraphatsara N, Yongchaiyudha S, Rungpitarangsi V, Chokechaijaroenporn O. 1996 Antidiabetic activity of Aloe vera $\mathrm{L}$ juice. II. Clinical trial in diabetes mellitus patients in combination with glibenclamide. Phytomedicine 3, 245-248.

Dahanayka S, Wijesundera RLC. 1994 - Penicillium purpurogenum on fruits of Averrhoa bilimbi in Sri Lanka. Journal of National Science Council of Sri Lanka 22(1), 23-24.

Dureja H, Kaushik D, Kumar N, Sardan, S. 2005 - Aloe vera. The Indian Pharmacist IV 38, 9-13.

El-Nagerabi SAF, E. Elshafie A, Alkhanjari SS. 2013 - Endophytic fungi associated with Ziziphus species and new records from mountainous area of Oman. Biodiversitas 14(1), 10-16.

Gilman JC. 2012 - A manual of soil fungi. Biotech Books, New Delhi, India pp. 254.

Gordon MC, David JN. 2001 - Natural product drug discovery in the next millennium. Pharmaceutical Biology 39, 8-17.

Gubler WD, Converse RH. 1994 - Diseases of strawberry (Fragaria x ananassa Duch.). In: Common Names for Plant Diseases 139-143.

Maiti S, Chandra R. 2002 - Cultivation of Aloe vera. National Research Center for Medicinal and Aromatic Plants, Boriavi, Anand, Gujrat. www.nrcmap.org.

Rabe T, Staden JV. 1997 - Antibacterial activity of South African plants used for medicinal purposes. Journal of Ethnopharmacology 56, 81-87.

Sagar A, Kaur R. 2010 - Study on fungal associates of Aesculus indica. Biological Forum - An International Journal 2(1), 49-52. 
Shukla M, Mishra M.K. 2012 - Mycoflora associated with five commonly used medicinal plants of Karaikal (U.T. of Puducherry). International Journal of Scientific and Research Publications 2(1), 1-4.

Yongchaiyudha S, Rungpitarangsi V, Bunyapraphatsara N, Chokechaijaroenporn. 1996 Antidiabetic activity of Aloe vera $\mathrm{L}$ juice. I. Clinical trial in new cases of diabetes mellitus. Phytomedicine 3, 241-243. 